\title{
A discrete platinum(II) amphiphile: construction, characterization and controllable self-assembly in different solvents
}

Yue Zhang, Ling Shi, Zhecheng Zhang, Qin Zhao, Yuehua Zhang,* and Yong Yao*

School of Chemistry and Chemical Engineering, Nantong University, Nantong, Jiangsu, 226019, P.R.

China.

E-mail: zhangyuehua969@126.com;yaoyong1986@ntu.edu.cn

\section{Supporting Information (9 pages)}

\begin{tabular}{|l|l|l|}
\hline 1. & Materials and methods & $\mathrm{S} 2$ \\
\hline 2. & Synthesis of bipyridylporphyrin derivative 1 & $\mathrm{S} 3$ \\
\hline 3. & Synthesis of AOM & $\mathrm{S} 4$ \\
\hline 4. & Self-assembly of $\boldsymbol{A O M}$ in water & S7 \\
\hline
\end{tabular}




\section{Materials and methods}

All reagents were commercially available and used as supplied without further purification. Deuterated solvents were purchased from Cambridge Isotope Laboratory (Andover, MA). Bipyridylporphyrin derivative $\mathbf{1}$ and water-soluble carboxylate ligand $\mathbf{3}$ prepared according to the published procedure. ${ }^{\mathrm{S} 1}$, ${ }^{\mathrm{S}}$ NMR spectra were recorded on a Varian Unity $400 \mathrm{MHz}$ spectrometer. Mass spectra were recorded on a Micromass Quattro II triplequadrupole mass spectrometer using electrospray ionization with a MassLynx operating system. UV/vis spectra were taken on a Perkin-Elmer Lambda $35 \mathrm{UV} /$ vis spectrophotometer. Transmission electron microscopy (TEM) investigations were carried out on a JEM-1200EX instrument. Dynamic light scattering measurements were performed on a goniometer ALV/CGS-3 using a UNIPHASE He-Ne laser operating at $632.8 \mathrm{~nm}$.

Simulation methods:

In this work, the density functional theory (DFT) calculation was performed using the $\mathrm{Dmol}^{3}$ code [S3]. The exchange-correlation interaction was treated by the generalized gradient approximation (GGA) with PBE functional [S4]. A double numerical quality basis set with d-type polarization function (DNP[S5]) was utilized for all the geometric optimizations, total energy calculations. The core electrons were modeled using effective core pseudopotentials (ECP) by Dolg[S6] and Bergner[S7]. All calculations were spinning unrestricted. The conductorlike screening model (COSMO) with dielectric constant of 78.54 was used to simulate a solvent environment for the calculation. The positions of all the atoms were fully relaxed until the following convergence criterion are met respectively: $0.002 \mathrm{Ha} / \AA$ for force, $10^{-5} \mathrm{Ha}$ for total energy and $0.005 \AA$ for displacement. The real space cutoff radius was $4.1 \AA$. The self-consistent field computations criterion was chosen to be $10^{-6} \mathrm{Ha}$. 
Scheme S1. Synthesis of bipyridylporphyrin derivative $\mathbf{1 .}$

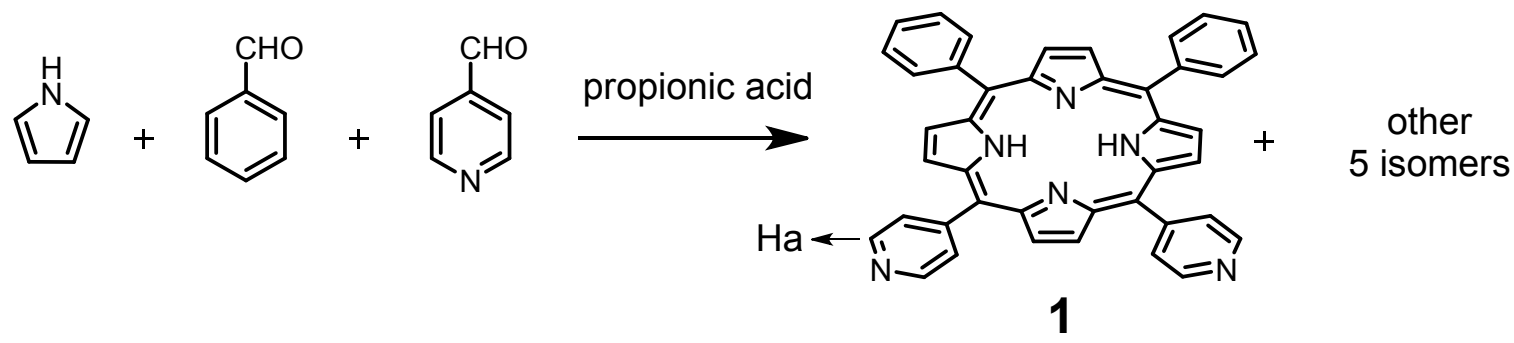

In a $500 \mathrm{~mL}$ round-bottomed flask pyrrole $(7.0 \mathrm{~mL}, 100 \mathrm{mmol})$, benzaldehyde $(5.0 \mathrm{~mL}, 50 \mathrm{mmol})$, and $4-$ pyridinecarboxaldehyde $(5.0 \mathrm{~mL}, 50 \mathrm{mmol})$ were refluxed in $250 \mathrm{~mL}$ of $99 \%$ propionic acid for $1 \mathrm{~h}$. The reaction mixture was then cooled and allowed to stand overnight. Filtration and methanol washing afforded $2.10 \mathrm{~g}$ (yield: $13 \%$ ) of a purple power product. The product was analyzed by silica gel thin layer chromatography and found to be a mixture of 1 and other five possible porphyrin isomers. ${ }^{\mathrm{S} 1}$

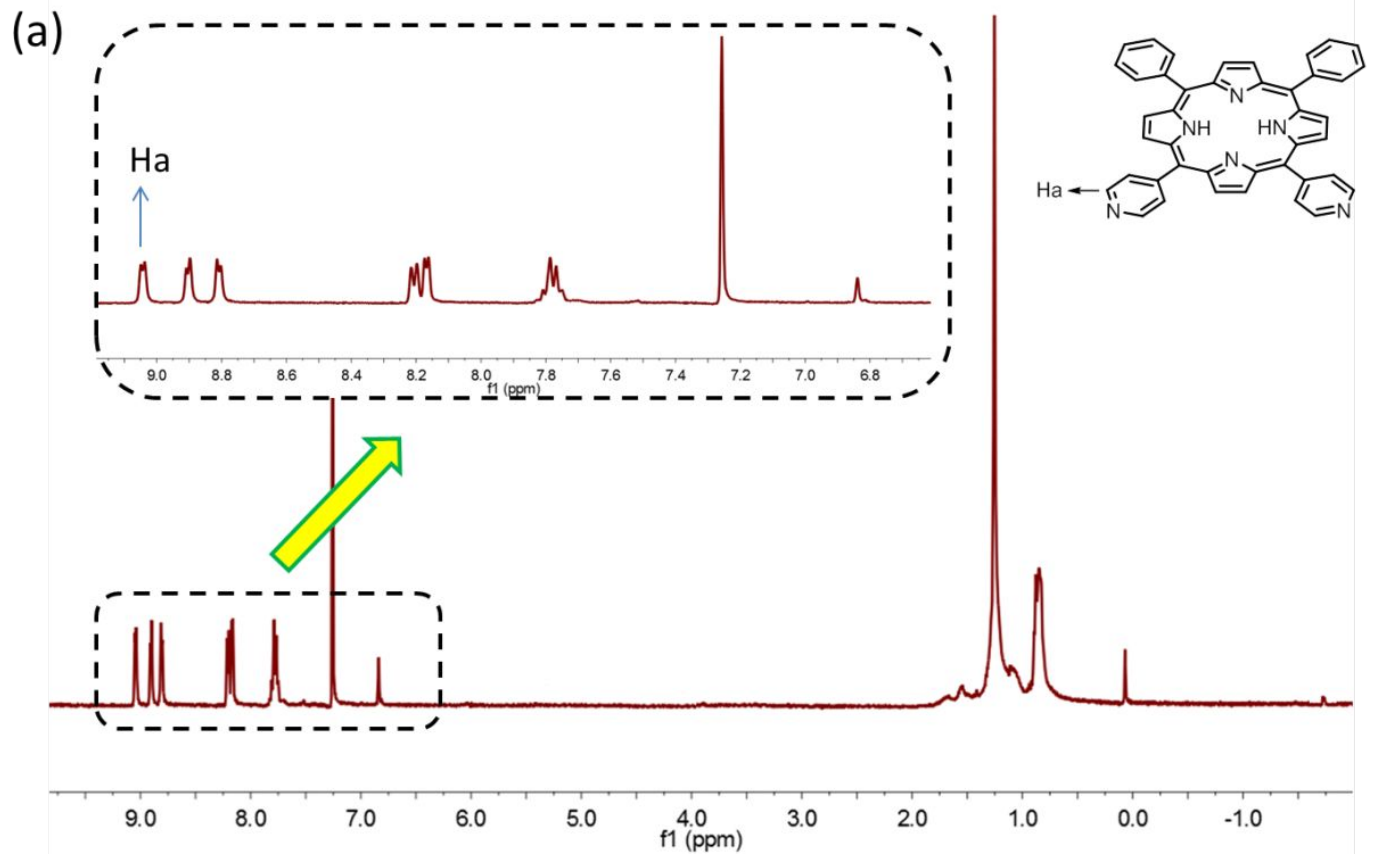


(b)

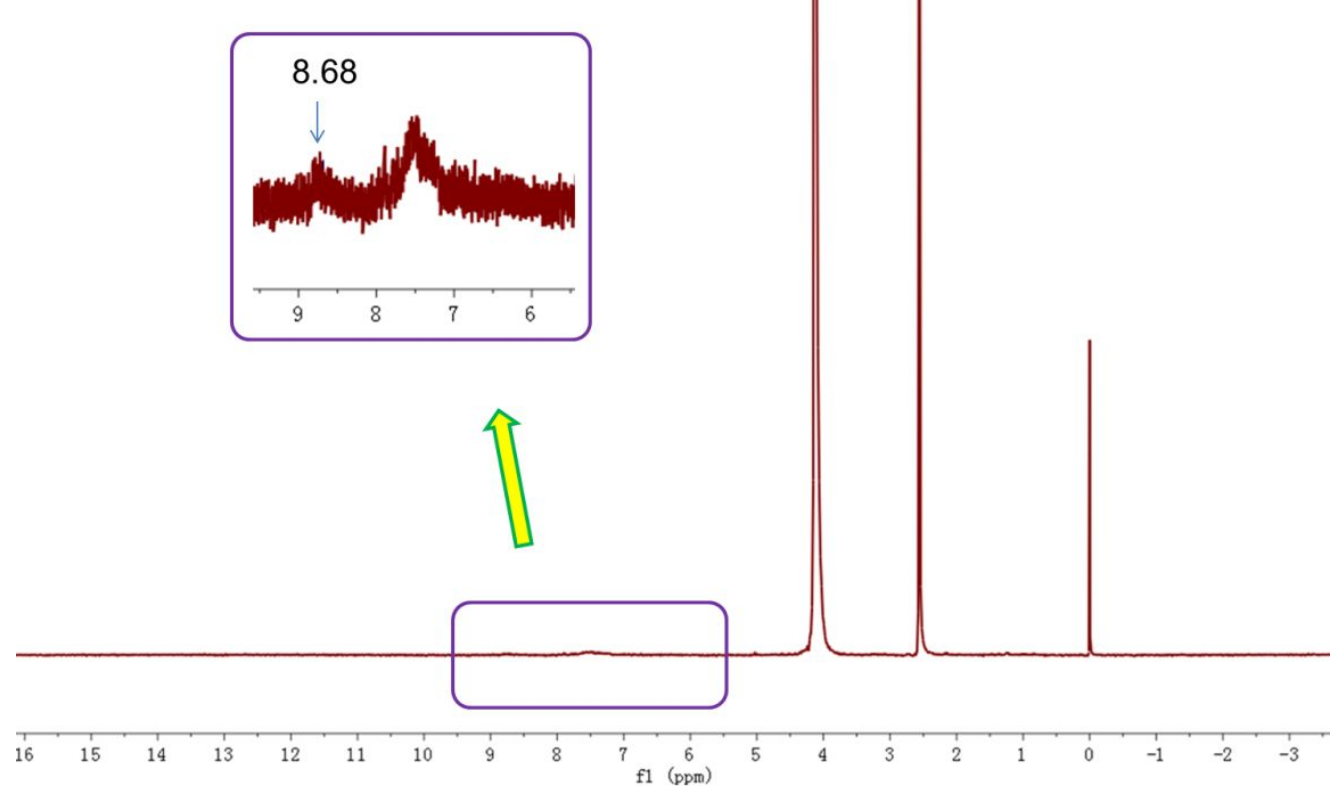

Figure S1. (a) ${ }^{1} \mathrm{H}$ NMR spectrum ( $\left.400 \mathrm{MHz}, \mathrm{CDCl}_{3}, 293 \mathrm{~K}\right)$ of bipyridylporphyrin derivative 1. (b) ${ }^{1} \mathrm{H}$ NMR spectrum (400 MHz, $\mathrm{CD}_{3} \mathrm{COCD}_{3} / \mathrm{D}_{2} \mathrm{O}, 293 \mathrm{~K}$ ) of bipyridylporphyrin derivative 1

\section{Synthesis of $\boldsymbol{A O M}$}

Scheme S1. Synthesis of AOM.
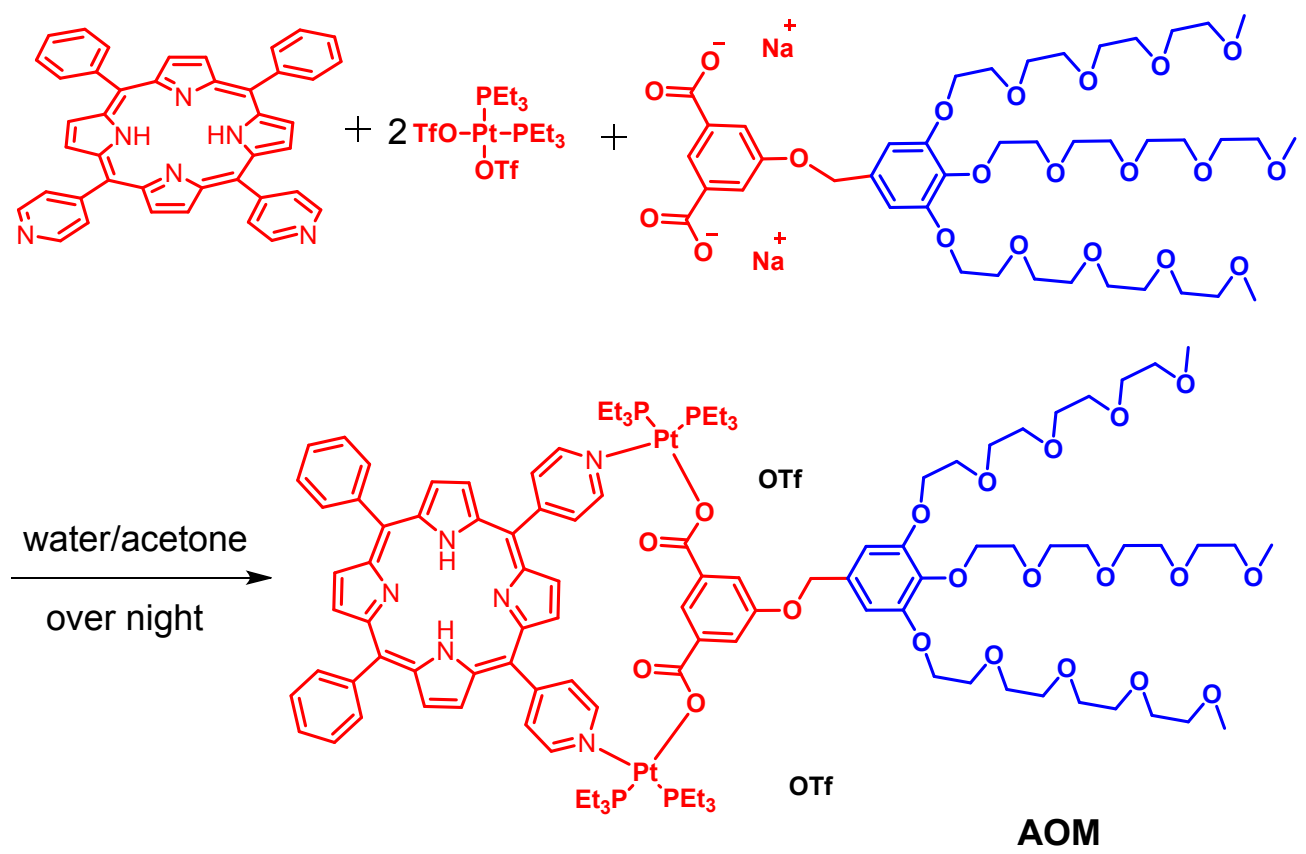
In a 1:2:1 molar ratio, $O$-bipyridylporphyrin $(0.93 \mathrm{mg}, 1.50 \mu \mathrm{mol}), 90^{\circ} \mathrm{Pt}(\mathrm{II})$ acceptor $(2.20 \mathrm{mg}, 3.00 \mu \mathrm{mol})$ and water soluble carboxylate ligand $(1.44 \mathrm{mg}, 1.50 \mu \mathrm{mol})$ were placed in a $4 \mathrm{~mL}$ vial, followed by addition of $\mathrm{H}_{2} \mathrm{O}(0.5 \mathrm{~mL})$ and acetone $(2.5$ $\mathrm{mL}$ ). After stirring overnight at $60^{\circ} \mathrm{C}$, all solvent was removed by $\mathrm{N}_{2}$ flow and the solid was dried under vacuum. Acetone (1.0 $\mathrm{mL}$ ) was then added into the vial, and the solution was stirred for $5 \mathrm{~h}$ at room temperature. After storage in a refrigerator for 1 h, the mixture was filtered to remove insoluble materials. The resulting AOM was precipitated with diethyl ether, isolated, and dried under reduced pressure $\left(2.92 \mathrm{mg}\right.$, yield: $73 \%$ ) and then re-dissolved in $\mathrm{D}_{2} \mathrm{O} /$ acetone- $d_{6}$ for characterization. ${ }^{1} \mathrm{H}$ NMR $\left(400 \mathrm{MHz}, \mathrm{D}_{2} \mathrm{O} /\right.$ acetone- $\left.d_{6}\right): \delta=8.71(\mathrm{~d}, J=4.0 \mathrm{~Hz}, 4 \mathrm{H}), 8.38(\mathrm{~s}, 1 \mathrm{H}), 8.10(\mathrm{~s}, 1 \mathrm{H}), 7.70(\mathrm{~d}, J=4.0 \mathrm{~Hz}, 2 \mathrm{H}), 7.55-7.30(\mathrm{~m}$, $14 \mathrm{H}), 6.65(\mathrm{~s}, 2 \mathrm{H}), 6.44(\mathrm{~s}, 2 \mathrm{H}), 6.11(\mathrm{~s}, 2 \mathrm{H}), 6.00(\mathrm{~d}, J=4.0 \mathrm{~Hz}, 2 \mathrm{H}), 5.11(\mathrm{~s}, 2 \mathrm{H}), 4.17(\mathrm{t}, J=4.0 \mathrm{~Hz}, 6 \mathrm{H}), 3.81(\mathrm{t}, J=4.0 \mathrm{~Hz}$, $6 \mathrm{H}), 3.61-3.36(\mathrm{~m}, 44 \mathrm{H}), 1.42-1.38(\mathrm{~m}, 20 \mathrm{H}), 1.00(\mathrm{t}, J=4.0 \mathrm{~Hz}, 36 \mathrm{H}) .{ }^{31} \mathrm{P}\left\{{ }^{1} \mathrm{H}\right\} \mathrm{NMR}\left(\mathrm{D}_{2} \mathrm{O} /\right.$ acetone, $\left.121.4 \mathrm{MHz}\right): \delta=7.82(\mathrm{~d}$, ${ }^{2} J_{\mathrm{p}-\mathrm{p}}=20.6 \mathrm{~Hz}, 195 \mathrm{Pt}$ satellites, $\left.{ }^{1} J_{\mathrm{pt}-\mathrm{p}}=3,241 \mathrm{~Hz}\right), 1.79\left({ }^{2} J_{\mathrm{p}-\mathrm{p}}=20.6 \mathrm{~Hz},{ }^{195} \mathrm{Pt}\right.$ satellites, $\left.{ }^{1} J_{\mathrm{pt}-\mathrm{p}}=3,460 \mathrm{~Hz}\right)$. ESI-MS $\left(\mathrm{C}_{103} \mathrm{H}_{152} \mathrm{~N}_{6} \mathrm{O}_{20} \mathrm{P}_{4} \mathrm{Pt}_{2}\right) \mathrm{m} / \mathrm{z}$ : [M-2OTf $]^{2+}$ at $m / z=1184.84$.

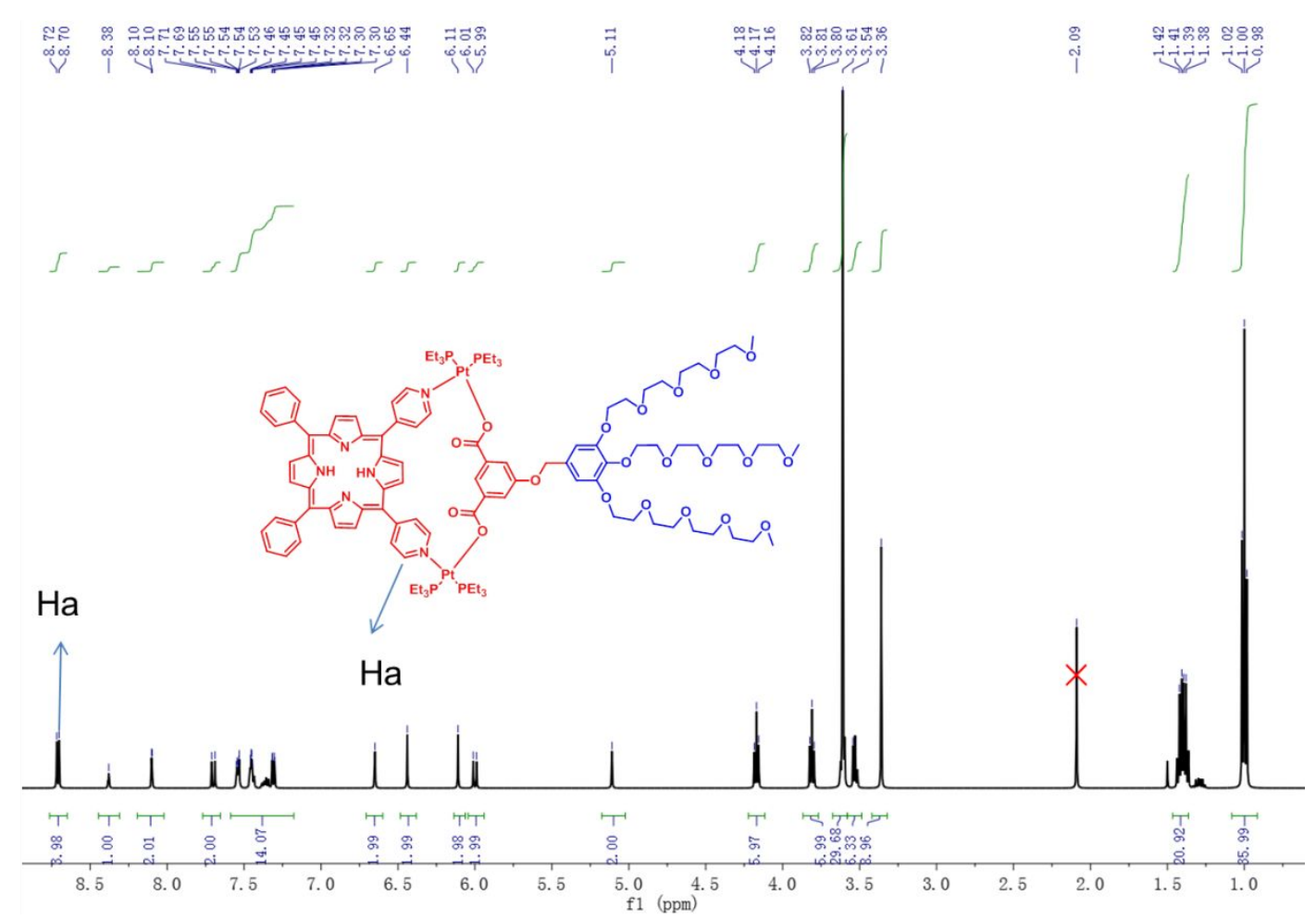

Figure S2. ${ }^{1} \mathrm{H}$ NMR spectrum (400 MHz, $\mathrm{D}_{2} \mathrm{O} /$ acetone- $d_{6}, 293 \mathrm{~K}$ ) of AOM. 


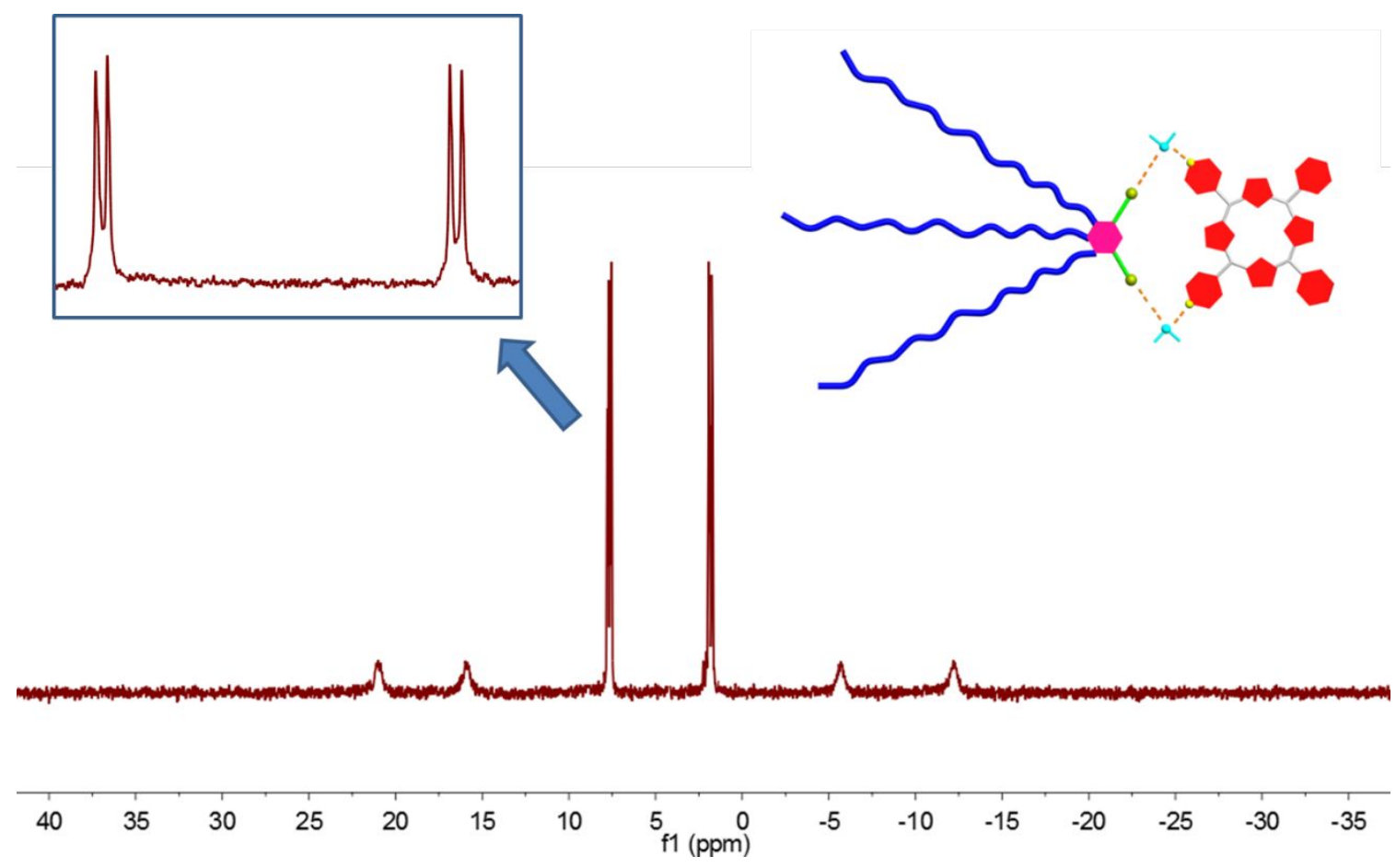

Figure S3. ${ }^{31} \mathrm{P}\left\{{ }^{1} \mathrm{H}\right\}$ NMR spectrum (acetone, room temperature, $121.4 \mathrm{MHz}$ ) and expanded version (inset) of AOM.

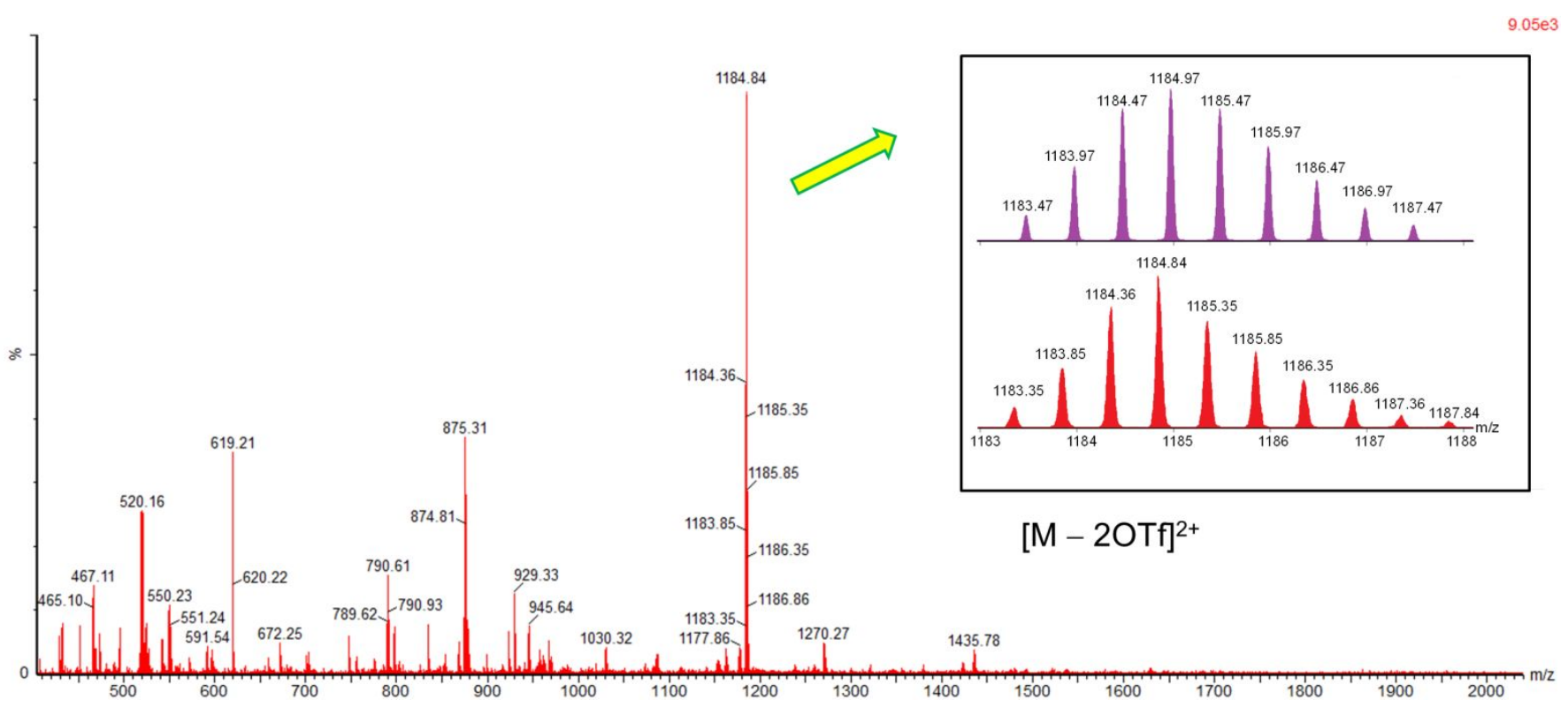

Figure S4. Experimental (red) and calculated (blue) ESI-TOF-MS spectra of AOM [M-2OTf $]^{2+}$. 


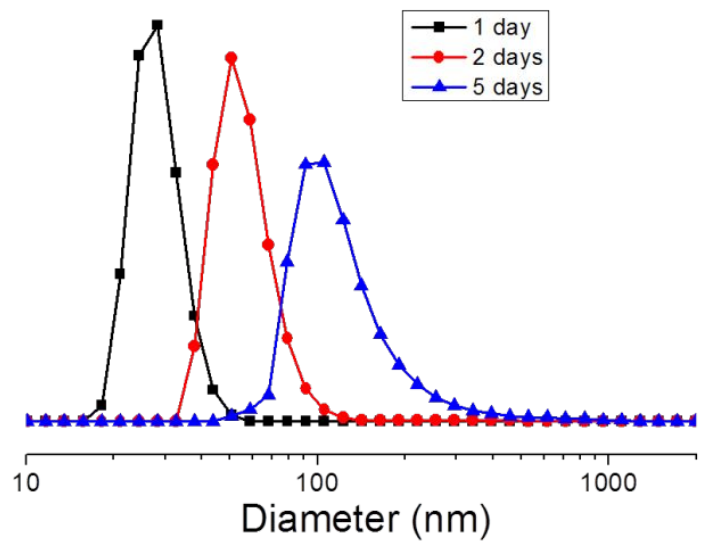

Figure S5. DLS results at a scattering angle of $90^{\circ}$ of $\mathbf{A O M}$ solution $\left(1.00 \times 10^{-4} \mathrm{M}\right)$ in water with different selfassembly time.

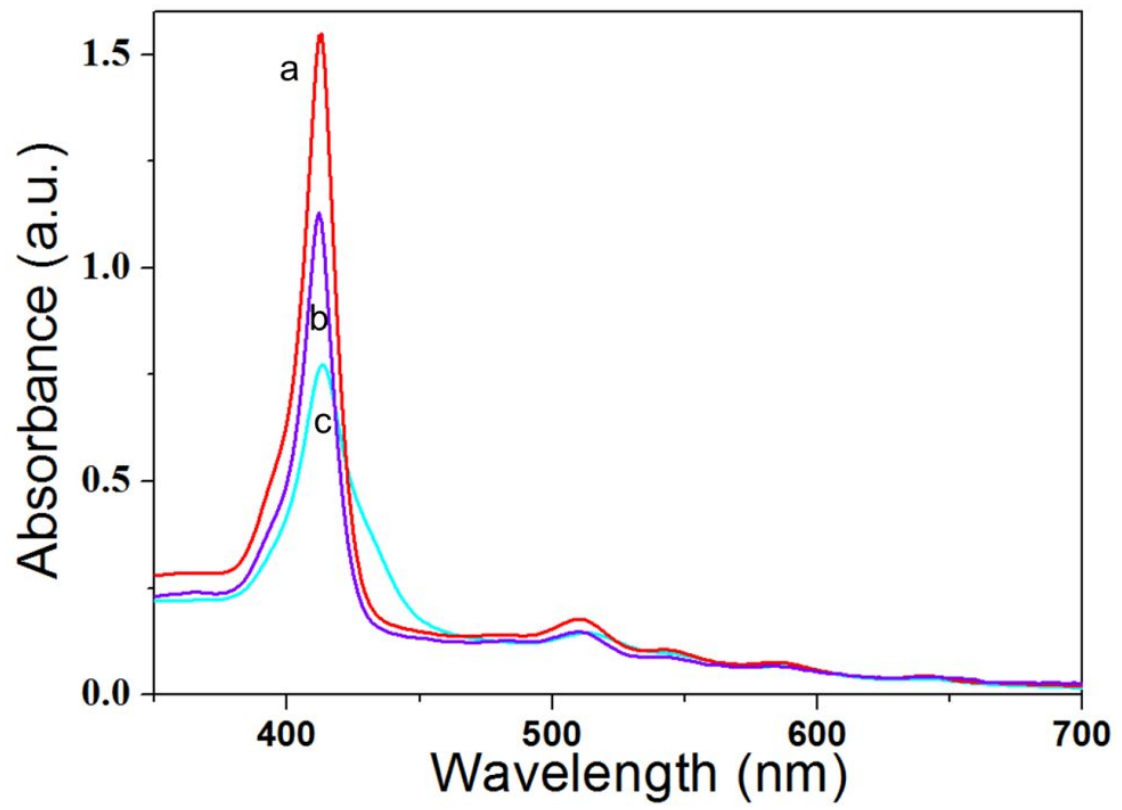

Figure S6. UV-vis spectra of AOM in water with different self-assembly time: (a) one day; (b) two days; (c) five days. 


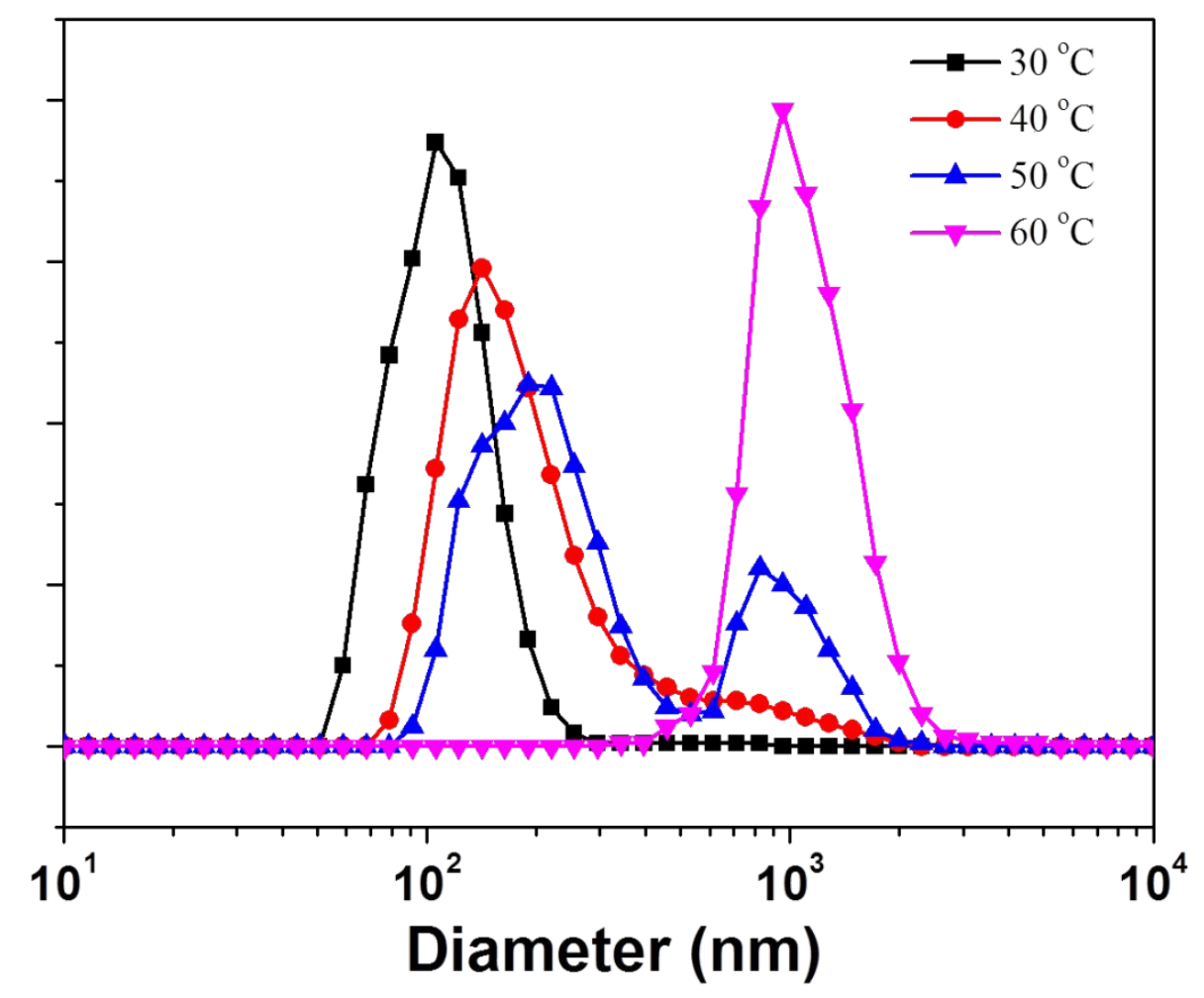

Figure S7. DLS results at a scattering angle of $90^{\circ}$ of $\mathbf{A O M}$ solution $\left(1.00 \times 10^{-4} \mathrm{M}\right)$ in water at different selfassembly temperature.

(a)
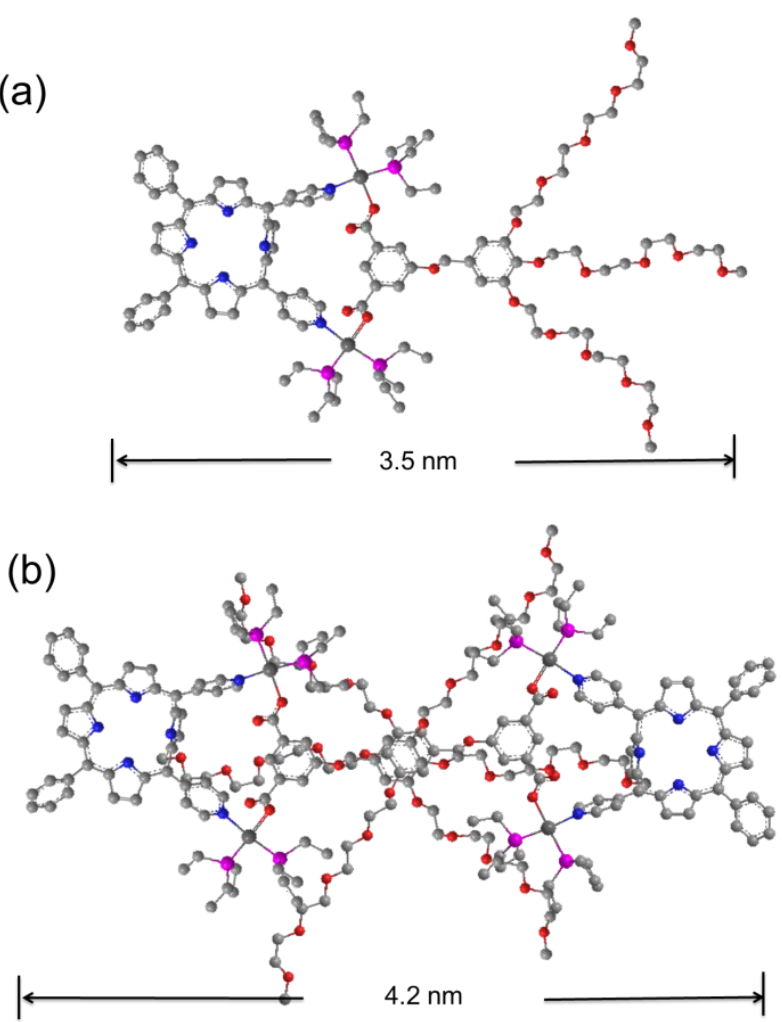

Figure S8. Minimize energy structure of AOM calculated by DFT method. 
References:

S1. Fleischer, E. B.; Shachter, A. M. Inorg. Chem. 1991, 30, 3763-3769.

S2. Yan, X.; Li, S.; Cook, T. R.; Ji, X.; Yao, Y.; Pollock, J. B.; Shi, Y.; Yu, G.; Li, J.; Huang, F.; Stang, P. J. J. Am. Chem. Soc. 2013, 135, 14036-14039.

S3. Delley B (2000) From molecules to solids with the DMol ${ }^{3}$ approach. J Chem Phys 113 (18):7756-7764

S4. Perdew JP, Burke K, Ernzerhof M (1996) Generalized Gradient Approximation Made Simple. Phys Rev Lett 77 (18):3865-3868

S5. Delley B (1990) An all-electron numerical method for solving the local density functional for polyatomic molecules. $J$ Chem Phys 92:508-517

S6. Dolg M, Wedig U, Stoll H, Preuss H (1987) Energy-adjusted abinitio pseudopotentials for the first row transition elements. J Chem Phys 86 (2):866-872

S7. Bergner A, Dolg M, Küchle W, Stoll H, Preuß H (1993) Ab initio energy-adjusted pseudopotentials for elements of groups 13-17. Mol Phys 80 (6):1431-1441 